\title{
The USU Mild/Moderate Distance Degree and Licensure Program: Where We've Been and Where We're Going
}

\author{
Nancy Glomb ${ }^{1}$ \\ Benjamin Lignugaris/Kraft \\ Ronda Rudd Menlove \\ Utah State University
}

\begin{abstract}
Providing access to quality special education teacher training programs for all qualified applicants is particularly pertinent in light of the national shortage of special education teachers. In addition, there are increasing numbers of students enrolling in Utah schools, and a percentage of that increased enrollment includes students with disabilities. The Mild/Moderate Distance Degree and Licensure Program at Utah State University began in 1995 to help address this shortage. Initially, the program was designed to recruit and prepare qualified mild/ moderate special education teachers in one rural area of the state that includes two school districts. Over time, the program expanded to other areas of the state in an effort to provide accessibility to qualified individuals for whom financial and family obligations preclude their ability to enroll in and attend a traditional campus-based program. Currently, 108 individuals have graduated from the program and are employed in 27 Utah school districts. In this article, the authors discuss the development of the distance program over the past decade, what worked, and future directions in distance education delivery at Utah State University.
\end{abstract}

Children with disabilities in today's schools are ensured equal access to a public education through the Individuals with Disabilities Education Act (IDEIA, 2004). This legislation levels the playing field for many children who may otherwise not be able to fully access and benefit from a quality educational experience and ensures that highly qualified special education teachers will guide the way. However, many capable individuals who aspire to become highly qualified special education teachers cannot fulfill their dream because they cannot access traditional teacher preparation programs. For individuals who live and work in rural and remote areas, geographic proximity alone presents a significant obstacle. For others who may be within a reasonable commuting distance from a traditional university-based teacher preparation program, financial and family obligations may preclude their enrollment in a traditional campus-based program.

Providing access to quality special education teacher preparation programs for all qualified applicants is particularly pertinent in light of the critical shortage of special education teachers (Katsiyannis, Zhang, \& Conroy, 2003). Utah has experienced critical shortages of special education teachers for more than 40 years, and special education positions continue to be among the highest ranked shortages (Utah State Office of Education, 2008). In addition, there are increasing numbers of students enrolling in Utah schools (Perlich, 2008) along with a concomitant increase in students with disabilities.

\section{The Mild/Moderate Distance Degree and Licensure Program}

The Utah State University (USU) Mild/Moderate Special Education Distance Education Program began in 1995 to address the critical shortages of teachers for students with mild/moderate disabilities in one remote area of the state. The program, initially supported through a U.S. Department of Education personnel preparation grant, started with eight students preparing to fill special education positions in two rural school districts. Since 1995, the program has expanded statewide and receives over 200 applications for every 2 -year cohort. Over $90 \%$ of the students who participate in the program are female, work as paraeducators in Utah schools, and are raising school-age children. Forty students are selected to participate in each 2 -year cohort, and, to date, 27 Utah school districts participate with and are served by this distance teacher preparation program.

Students who participate in the USU distance education program fulfill the same requirements as students who participate in the traditional campusbased program, and successful completion of this program leads to a Bachelor's of Science degree in special education and eligibility for a mild/moderate teaching license in Utah. Students attend hybrid broadcast/online courses through regional USU campuses and centers throughout the state. Courses cover subjects such as applied behavior analysis, effective instruction techniques, legal and ethical aspects of special education, procedures for transitioning high

\footnotetext{
${ }^{1}$ Address all correspondence to Nancy Glomb (nancy.glomb@usu.edu), Department of Special Education and Rehabilitation, Utah State University, Logan, UT.
} 
school students to adult life, and effective communication and collaboration between educators, parents, and related service personnel. Students also participate in classroom-based practica in local schools during each semester of the program.

\section{History of Delivery Systems}

As the state's land grant institution, USU has a decades-long history of providing outreach services to rural and remote areas. When the Mild/Moderate Distance Degree and Licensure Program began in 1995 , faculty traveled by small plane, or several hours by car, to provide face-to-face instruction to eight students in Vernal, UT. In 1997, USU partnered with the Utah Educational Network (UEN) to broadcast classes via a statewide satellite system, and the program began its broadcast history. With the advent of broadcast capabilities, delivery to additional rural areas of the state became feasible. In 2007, USU and UEN broke ground again by introducing a statewide, internet-based videoconferencing delivery network for all USU interactive broadcast courses (http:// distance.usu.edu/htm/about). In addition, the introduction of university-wide email and web-based course management systems during the 1990s increased the connection between USU faculty and distance education students.

The Mild/Moderate Distance Degree and Licensure Program also pioneered program-specific technologies for improving connections between USU faculty, distance education students, and school district personnel across the state. In 1999, several Sorenson EnVision web-conferencing systems were yoked together to allow multi-site conferencing. This permitted more personal and frequent interaction between faculty and students than the university-wide system allowed (Menlove, Hansford, \& Lignugaris/Kraft, 2000). The EnVision system was used for instruction as well as supervision of distance students in classroom-based practica, and, although this system was cost-prohibitive for large scale use, it set the stage for the continued evolution of webbased conferencing uses in the program. The EnVision System was replaced with a multisite Polycom delivery system, which was later upgraded to a high definition internet video conferencing system. Currently, faculty, students, program advisors, and school district personnel use an inexpensive web conferencing package to connect with each other for a wide variety of class assignments and advising activities. Faculty also use multi-user virtual environments such as Second Life ${ }^{\mathrm{TM}}$ (Foster, 2007) to provide isolated students with opportunities for group activities.

\section{History of Program Design}

The USU program was initially designed to be a replication of the campus-based program with respect to both the content and design of the courses and practica. Students were required to attend two classes every week for six consecutive semesters, including summers, and the classes were taught "back to back" from 4:30 to 10:00 PM. Faculty designed and delivered distance course sections in exactly the same manner as their campus-based sections, in that all instruction was synchronous.

Over time, it became clear that "business as usual" did not meet the needs of our distance learners. Most of the students in the USU distance program are full-time paraeducators who are also raising families. In 2005, an analysis of program attrition and interviews with students who left the program revealed that the traditional weekly schedule, especially during summer semesters, caused otherwise bright and capable students to "burn out." This led us to examine alternative ways to design our courses to provide our distance learners with more flexibility. During the 2006 summer semester, courses were delivered in a hybrid, or blended, format for the first time, with approximately $40 \%$ of course content being delivered online via asynchronous modules and approximately $60 \%$ via live interactive broadcast sessions. Students attended live classes every 2 to 3 weeks and completed activities within the web-based asynchronous modules in between class sessions. The asynchronous modules included voiced-over PowerPoint slides, study guides, and video clips. At the end of the semester, course evaluation responses to the hybrid format were very favorable. Students stated that the asynchronous modules allowed them the flexibility to access course content during opportune times, such as Saturday mornings when their children went to soccer practice or late at night after their children were asleep. Many students also reported that the asynchronous modules allowed them to review the presentations for clarification. Finally, the hybrid format during the summer allowed our students to take much needed vacation time with their families. Students either accessed the web-based modules during their vacations or scheduled their time so that online activities were completed before their vacations.

The manner in which distance students are placed in and supervised during practica also evolved over time. Initially, we placed our distance learners in classrooms with USU graduates, and USU faculty traveled long distances four to five times during a semester to observe and supervise students. To decrease the amount of travel time, cameras were placed in classrooms, and the Sorensen EnVision system was used to observe our practicum students from the main campus (Falconer \& Lignugaris/Kraft, 2002). As the program increased its geographic footprint, this system became cost prohibitive, and it became necessary to rely on local teachers to provide supervision. USU graduates 
participated in one-day workshops to learn our supervision protocol, and faculty traveled to the localities to conduct at least one reliability check during the semester. While this decreased the amount of time spent traveling to the distance sites, it increased the amount of time spent "trouble shooting" during the semester. Although the distance supervisors are adept at accurately recording teaching behaviors, many are not experienced enough or confident enough to provide the necessary corrective feedback. Distance supervisors often waited until the end of the semester to share their concerns with university faculty, making remediation difficult. This led us to revisit the use of desk top conferencing equipment for supervising our distance students, and we currently use a package that includes a Logitech $^{\mathrm{TM}}$ QuickCam Orbit camera, a BlueAnt ${ }^{\mathrm{TM}}$ Supertooth Light hands free speakerphone, a Bluetooth $^{\mathrm{TM}}$ Dongle wireless adapter, and a Caliphone $^{\mathrm{TM}}$ USB headset. Students and school district personnel are given a user-friendly protocol for installing the hardware on a classroom computer, and USU faculty schedule student observations through Google ${ }^{\mathrm{TM}}$ Illuminate. Local teachers and school district personnel are still trained to observe our distance students in their practicum classrooms, and the combination of live and electronic supervision provides our distance students with high quality supervision and timely feedback. The hardware and software cost less than $\$ 200$, making this package an affordable option for use with all of our distance students.

The changes that we made to accommodate our distance learners have had a profound influence on the structure of the campus-based program. Most of the courses in both the distance and campus-based programs are now taught in a hybrid format, and campus-based supervisors are realizing the time efficacy of electronic supervision.

\section{History of Student Supports}

When the mild/moderate preparation program began, few supports were available for distance students, and attrition rates for early cohorts were between 30 and 60 percent. In 2005, phone interviews with non-completers indicated that many dropped out because they felt isolated, overwhelmed, and disconnected from their professors and classmates. They lacked the support and cohesiveness that occurs in campus-based learning communities, which tend to form naturally in that students walk to and from classes together, arrange times to study together, and meet in the university student center for breaks. To address this need, we hired graduates of the distance program to serve as local mentors and establish regional learning communities to support program participants (Glomb, Midenhall, Mason, \& Salzberg, in press.) Site mentors are program graduates who are employed as special education teachers in a Utah public school district and are recommended by their district supervisor. Site mentors are hired by USU through a Utah State Office of Education grant to work 2 to 3 hrs per week with the distance students in their locality. They are compensated for their time and travel that is more than $\mathbf{3 0}$ miles from their home. A mentor's primary responsibility is to provide opportunities for emotional and academic support outside of class time. In essence, they engineer their learning community so it takes into account the geographic, job, and family constraints of the distance learners within their locality. For example, several participants at one regional center travel an hour or more from large ranches to attend broadcast classes. For these participants, attending additional group activities during the week can be a hardship. However, a common activity for these students and their mentor is Saturday morning $4 \mathrm{H}$ horsemanship, and the mentor uses that time to interact with program participants about assignments and program demands.

Currently, nine site mentors are employed throughout the state, and an open source website (http://mmdc.sped.usu.edu/) provides them with a forum for discussing ideas for activities and problem solving difficult student issues. The website was developed in Moodle ${ }^{\mathrm{TM}}$ with support from a U.S. Department of Education grant. The website also provides school district personnel with opportunities to interact with site mentors and distance program staff through dedicated discussion forums and scheduled chat sessions. For example, one particular discussion forum was developed in response to school district administrators' questions about student teaching requirements. Because the distance program collaborates with 27 different school districts across the state, scheduling synchronous "real time" meetings to provide information and training to all stakeholders can be challenging. The discussion forum allows USU faculty and staff to post important information, updates, and clarifications, and email alerts are sent to the stakeholders when new information is available. The asynchronous nature of the discussion forum allows each individual to access the information when they are able, and the activity report feature in Moodle ${ }^{\mathrm{TM}}$ allows faculty to track who has accessed each posting.

In addition to the site mentor network, midsemester progress meetings were added in 2006 to ensure that all students receive the information they need to be successful in the program. Each semester, the distance program academic advisor meets with each student to discuss his/her progress in the program and provide information about important events or deadlines. Meetings may take place at the student's regional center or via the desktop conferencing system. The meetings also provide faculty with an opportunity to review the status of each distance student and 
develop and implement timely support and remediation plans when necessary.

\section{Past Perspectives and Future Directions}

To date, 137 individuals have graduated from the distance mild/moderate teacher preparation program and are employed in Utah schools. Our program graduates are in high demand, and we continue to receive hundreds of applications every year. Over time, we adapted and adjusted the design and delivery of our program while maintaining content knowledge and performance competencies. Persistent and difficult program problems are met by examining student support and course delivery variables. The result thus far is an increase in program graduation rates from $40 \%$ to $75 \%$.

Distance education is changing the way rural Utahns perceive higher education. As with other rural areas in America, improvements in technology and service delivery make distance education an attractive option for many individuals who, in earlier years, might have relocated to USU's main campus or foregone a higher education. Interestingly, enrollment in our distance program continues to be robust, while enrollments in our campus-based teacher preparation programs are waning. Distance education is no longer the only option for some-it is the best option for many. As we look to the future and consider the development of new distance teacher preparation programs, we have also looked back over the past decade of our mild/moderate distance education program and considered what has contributed to its success. In doing so, we suggest that the following five points are critical to the development and maintenance of a successful distance teacher preparation program:

1. Be responsive to the specific needs of your distance learners.

Distance learners are not all alike, and one size does not fit all in distance education. Our distance program has changed over time in response to the needs and characteristics of our learners. Moreover, we expect that it will change in the future as we discover better and more flexible teaching technologies and as we interact with more culturally diverse learners.

2. Be willing to experiment and take risks.

Being responsive to the diverse needs of distance learners requires that faculty step out of their comfort zones at times and try new things. Although the learning curve may sometimes be steep, the pay off, as we have seen in our distance program, is well worth the climb. Not every "experiment" will be effective, and if we are adjusting in response to student performance and feedback, our experimentations will lead to productive innovations. At the same time, other distance educators are experimenting with new ways of delivering programs. If we share our experiences as a community of, distance educators, we all stand to benefit.

3. Implement the principles of Universal Design by delivering content using a variety of approaches.

Responding to the specific needs of distance learners, and experimenting with new and innovative ideas, are consistent with the principles of universal design (http:// www.design.ncsu.edu/cud/about_ud/ udprinciplestext.htm) Programs that provide equitable and flexible access to all resources, and use evidence-based instructional practices to ensure that necessary content knowledge is communicated effectively to all students, provide powerful learning experiences for all students.

4. Develop strong, cooperative partnerships with school districts and be "culturally aware."

In traditional teacher education programs, preservice teachers reside close to campus, and, in most cases, they are placed for practica in schools that are readily accessible to faculty. In addition, faculty tend to be familiar with, and in many cases part of, the culture of the communities where these schools are located. In distance education programs, students may be placed in schools that represent a wide continuum of cultures and may be located at significant distances from where faculty live and work. For these reasons, collaborative partnerships with local districts and close working relationships with teachers and administrators in affiliated districts are critical components for success. While cooperating teachers and district based supervisors at a distance must learn how to use evidence-based supervision systems and strategies for shaping effective teaching behaviors, they also provide valuable insights into the interaction of local cultures with university expectations. Working closely with cooperating teachers and district based supervisors fosters trust and leads to shared decision making, and, as school district personnel gain program experience, they begin to understand what is required to prepare competent teachers.

5. Remember the power of direct human interaction.

Importantly, teaching is a social profession. Teachers interact with other professionals, parents, and students. In rural communities, it is not unusual to have one special education teacher, and it is not unusual to have one preservice teacher at a distance education delivery site. It is critical that we utilize creative technological approaches such as web forums, Facebook ${ }^{\mathrm{TM}}$, or Twitter ${ }^{\mathrm{TM}}$ to foster 
networking and interaction among program participants. First, this gives us opportunities to evaluate how potential teachers might interact with others in schools and suggest strategies that might make them stronger advocates for students with disabilities. Second, in rural settings, building technology-mediated interactions with colleagues provides a foundation for lifelong professional development and relieves the professional isolation that many rural special educators face.

\section{References}

About Us: Regional Campuses and Distance Education, Utah State University. Retrieved August 5, 2009 from http://distance.usu.edu/htm/ about

Falconer, K., B., \& Lignugaris/Kraft, B. (2002). A qualitative analysis of the benefits and limitations of using two-way conferencing technology to supervise preservice teachers in a remote location. Teacher Education and Special Education, 25, 368-385.

Foster, A. (2007). Professor avatar: In the digital universe of Second Life, Classroom instruction also takes on a new personality. Chronicle of Higher Education, 54(4), A24.

Glomb, N., Midenhall, T., Mason, L., \& Salzberg, C. (in press). Reducing Isolation through Regional Mentors and Learning Communities: A Way to Support Rural Learners. Rural Special Education Quarterly.

Individuals with Disabilities Education Improvement Act of 2004,

\section{Final Thoughts}

Distance education programs are here to stay and are becoming an increasingly popular option for many individuals in rural areas. To be responsive to the needs of our distance learners, we need to work together as a community of distance educators to identify and articulate best practices in distance education. Making careful, data-based decisions about the design and delivery of our programs and collaborating with each other will help to advance the field.

\section{U.S.C.A. $\$ 1400$ et seq.}

Katsiyannis, A., Zhang, D., \& Conroy, M. A. (2003). Availability of special education teachers: Trends and tests. Remedial and Special Education, 24(4), 246-253.

Menlove, R., Hansford, D., \& Lignugaris/Kraft, B. (2000). Creating a community of distance learners: Putting technology to work. Proceeding from the Annual Conference of the American Council on Rural Spccial Education, Alexandria, VA. (ERIC Documentation Reproduction Service No. ED 439 890).

Perlich, P. (2008). Utah's demographic transformation: A view into the future. Utah Economic and Business Review, 68(3), 1-11.

Utah State Board of Education. (2008). Teaching Field Index of Criticality for Utah T.H. Bell Teaching Incentive Loan Program. Available: Educator Quality and Licensing, Utah State Office of Education, Salt Lake City. 
Copyright of Rural Special Education Quarterly is the property of ACRES and its content may not be copied or emailed to multiple sites or posted to a listserv without the copyright holder's express written permission. However, users may print, download, or email articles for individual use. 